UDC 316.6

Srbuhi GEVORGYAN

Lida ARAMYAN

SOna MAKICHYAN

Ruben MKRTCHYAN

\title{
PSYCHOLOGICAL MANIFESTATIONS OF TRANSFORMING VALUE ORIENTATIONS IN THE SOCIAL BEHAVIOUR OF THE INDIVIDUAL
}

\begin{abstract}
In the context of the development of modern society, there is a growing interest in the value system of the individual, especially in a transformational society. It forms a kind of the internal core of human culture, thereby determining the line of his behaviour at levels of personality-groupsociety. Analysis of the research data of students of the Khachatur Abovian State Pedagogical University shows that in the ranking of values self-regulation, safety, favour is more pronounced. Some values in relation to each other are in dynamic conflict, and some are not conflicting pairs. Thus, in modern society, a change in the structure of students' values reflects social mobility in favour of personal well-being.

Keywords: transformation, personality - social group - society, value orientations, selfregulation.

In the context of the development of modern society, there is a growing interest in the value system of the individual, especially in a transformational society, which in psychology is defined as the selective attitude of a person to material and spiritual values, a system of beliefs and preferences expressed in his behaviour, ensuring stability, behaviour and personality activities.

In the study of a complex, dynamic, multi-level value system, we emphasize the psychological conditions that ensure the effectiveness of introducing innovative technologies in education and science at the levels of personality - social group - society.

Today in psychology, the problem of value-orientation mechanisms is actively studied, with most studies devoted to traditionally distinguished institutions of socialization - the family, reference peer group, educational institutions, and professional group (Belinskaja, Tihomandrickaja, 2003; Goodman, 2007).

As for the "measurement" of the contribution of various environmental influences (or agents of socialization) to the formation of a system of values, in modern socio-psychological knowledge, there is an acute lack of conceptual and functional models of such processes and mechanisms.
\end{abstract}


This gap is associated with the methodological monotony, which forms the basis of such studies. Thus, the methodological approaches that have dominated over the past decades to the problems of value orientations are connected, as a rule, with the study of the internal structure and hierarchy of values according to their relative, subjective significance. (Vardomackij, 1992; Rokeach, 1979). Another widely spread research area focuses on a comparative study of the values of representatives of various ethnic groups and cultures (Fogarty, White, 1994; Schwartz, Sagiv, 1995; Smith, Dugan, 1996). For these purposes, as a rule, methodologies are applied, which include the assessment and scaling of statements, as well as biographical methods. (Goodman, 2007).

In our reality, there is a change in the value orientations of people under the influence of various circumstances, including economic insecurity. Philosophers, sociologists, political scientists note that a new moral and ethical atmosphere is taking shape in the country, values are being re-evaluated, their creative rethinking is underway. After the "velvet revolution", value orientations are gradually established in the public consciousness, reflecting the desire of modern man for leadership, success, power over others, etc. This is particularly pronounced in the youth, student environment, as well as in novice researchers. Currently, there are two main trends in the study of value orientations: the first is the desire to create generalized theories of the structure and functioning of value regulators of personal behaviour. The second is the study of value orientations acquires an applied, character. Value orientations form a kind of the internal core of human culture, thereby determining the line of his behaviour. Value orientations have two major qualities: high stability and variability, is an expression of a measure of dynamism and openness of society, its groups and individuals. Therefore, value orientations reflect at the same time, the individual and social character of human activity, on the basis of which his needs are met in various fields [5].

The theoretical analysis allowed us to identify 5 functions of value orientations: goal-setting, evaluation, motivation, self-regulation, and control.

1. The function of goal setting. Value orientations as one of the mechanisms of goal-setting orient people among the objects of the natural and social world, creating an orderly and meaningful picture of the world. They provide a basis for choosing from among the available alternatives goals and means, for the order of preferences, evaluating and selecting these alternatives, defining "boundaries of action", i.e. not only regulate but also direct these actions [4].

2. Evaluation function. Evaluation function causes a certain emotional attitude of the individual to different aspects and phenomena of life-based on personal experience. The valueoriented assessment enriches the ideas and concepts of students about people and about themselves, gives them the opportunity to compare their moral, labour, aesthetic and other 
qualities with the requirements of society. Consequently, the evaluation function acts as the supreme control body for the regulation of all stimulators of human activity, determining acceptable methods for their implementation.

3. Motivational function. Values acquire the qualities of real motives and sources of meaningfulness of being, leading to the growth and improvement of the individual in the process of their own consistent development [2, p.49-58]. K.A. Albuhanova-Slavskaya and A.V. Brushlinsky describe the role of semantic representations in the organization of the system of value orientations, which manifests itself in the following functions: acceptance (or denial) and realization of certain values; strengthening (or reducing) their significance; retention (or loss) of these values in time [1, p.219-221].

4. The function of self-regulation in the value orientations of the individual covers all levels of the system of motivators of human activity. The specificity of the action of value orientations is that they function not only as ways to rationalize behaviour, their action extends not only to higher structures of consciousness but also to those that are usually referred to as subconscious structures. They determine the direction of the will, attention and intelligence. [3, p.20]. Value orientations provide self-regulation of human activity, which consists in his ability to consciously solve the tasks before him, to exercise free choice of actions, to assert certain socio-moral values as his activity [ibid, p. 16].

5. The controlling function that monitors the levels of development of value orientations by the individual in the specific socio-cultural conditions of the development of society.

Summarizing and analyzing the theoretical approaches to the study of value orientations in the methodological basis of our research, we emphasized the "theory of universal content and structure of values" proposed by S. Schwartz and W. Bilski [6]. Within the framework of the proposed approach, values are considered as beliefs or concepts (associated with an extraoperative desired end state or human behaviour) that perform the function of controlling the selection and or evaluation of a course of conduct. The concept of S. Schwarz at the heart of any value orientation is based on desired, extra-operative goals, differing in degree of significance and impelling a person to action. The system of such goals is a specific motivational type. On the basis of philosophical and cultural analysis, the results of psychological studies of the value sphere of a person, literature, the author identifies 10 types of value orientation, or motivational types, which form a hierarchy depending on personal significance. The allocation of motivational types is based on the statement that there are universal human needs; therefore, S. Schwartz considers the proposed value orientations as general cultural and existing in different social groups. The author identifies three groups of universal human needs: 1) biological needs of a person, 2) the need for social interaction and management of this interaction, 3) needs related to the functioning and 
survival of the group. These universal needs are considered by a person or a group of people as specific goals that explain, coordinate and rationalize behaviour. In various combinations, they are present in all 10 motivational types identified by S. Schwarz. Existing individual differences in the preferences of a particular value orientation are associated with a unique combination of needs, temperament and social experience of each individual person. For the study of students' value orientations, a Schwartz value questionnaire was used, in which 89 students of Kachatur Abovian Armenian State Pedagogical University participated.

Analysis of students' values shows that in the first place is the value orientation of selfregulation / average value - 3.02 /, which shows self-confidence, openness to new experience, interaction, influences, expresses individual freedom of thought and behaviour, choice. The high importance of self-regulation is very characteristic of a modern student who seeks to stand out, act independently, become self-confident. The second place for students at the level of normative ideals is safety / average value - 2.76 /; the third place is favour/ average value - 2.72 /. According to Schwartz's theory, these two values also have a group orientation. The latter demonstrates an ethical position in maintaining close and positive relations with people around them, their wellbeing, as well as security, which are reflected in all relationships at the levels of personality - social group - society. Achievement for students at the level of personal preferences is at the 2nd place and at the 9th place - at the level of normative values.

Some values in relation to each other, are in dynamic conflict. For example, self-regulation and stimulation are on one side, and traditions, power, and universalism are on the other. Selfregulation and achievement contradict equality, tradition and security since there is a certain opposition between the independent views and actions of the individual and the preservation of traditions that is inherent in the modern generation. Universal human values and benevolence are contrary to power and achievement, since the acceptance of other people, groups equal and a friendly attitude towards their well-being are poorly combined with the achievement of their own goals and the superiority of power. The data show that some value orientations of students are the following, not contradictory pairs:

- Achievements and hedonism are associated with pleasure, self-confidence, sensual focus on yourself and the desire to get as much pleasure as possible.

- Hedonism and stimulation are combined with the desire to get a pleasant feeling

- Stimulation and self-regulation contain the desire for the development and dynamics of the individual.

Thus, in modern society, a change in the structure of students' values reflects social mobility in favour of personal well-being, rather than social interests and collectivism. 


\section{References}

Abul'hanova-Slavskaja, K. A. (1989) Filosofsko-psihologicheskaja koncepcija S. L. Rubinshtejna k 100-letiju so dnja rozhdenija / K.A. Abul'hanova-Slavskaja, A.V. Brushlinskij. - M.: Nauka, $248 \mathrm{s.}$

Vasiljuk, F.E. (1984) Psihologija perezhivanija (analiz preodolenija kriticheskih situacij) / F.E. Vasiljuk. - M.: Izd-vo MGU, 200 s.

Zdravomyslov, A.G. (1986) Potrebnosti, interesy, cennosti / A.G. Zdravomyslov. - M.: Politizdat, $222 \mathrm{~s}$.

Naumova, I. F. (1988) Sociologicheskie i psihologicheskie aspekty celena-pravlennogo povedenija / I.F. Naumova. M.,199 s.

Pochebut L.G., Mejzhis I.A. (2010) Social'naja psihologija. Piter /https://www.ereading.mobi/chapter.php/1034490/9/Meyzhis___Socialnaya_psihologiya.html

Schwartz, S.H., Bilsky W. Toward a theory of the universal content and structure of values: Extensions and cross-cultural replications // Journal of Personality and Social Psychology. 1990. Vol. 58, p. 878-891. 